The second part of this book will be more attractive for the literary scholar, who can find an in-depth analysis of three plays (The Winter's Tale, Othello and Hamlet) and its connections with current areas of discussion. In the chapter on The Winter's Tale, Prof. Bristol foregrounds the distortion of time as the playwright's device to portray contemporary social complexity, whereas Othello is considered a radical attempt to reveal the unlawful use of social institutions (marriage in this case). More interesting, from my point of view, is his reflection on the intelectual unacceptability of prominent conceptual features of these plays: the chauvinist picture of a passive female role and, in Othello, a blatantly racist presentation of character. Bristol sides with Bloom against the opinions of the so-called 'school of resentment': it is impossible to make a feminist or anti-racist reading of them, but their intrinsic literary value still makes Shakespeare the pivotal figure of the Western Literary Canon. The chapter on Hamlet is a grounded acknowledgement of the character as the archetypical 'genius' of Western modernity, although the relevance of using a comic strip (Calvin and Hobbes) to illustrate contemporary quotations of the play is hardly justifiable, specially for those of us who had never heard of it.

Shakespeare's skill at entrepreneurship is nothing he should have had to apologise for. Neither should the author of this book for its commercial intentions. One would recommend leaving aside an academic reluctancy to this kind of presentation; reading this text will certainly contribute to our understanding of this world-wide academic, social and economical phenomenon which, whether we like it or not, Shakespeare has (been) turned into.

John D. Sanderson

\title{
Daniel Statman, Moral Dilemmas. Amsterdam, Rodopi, 1995. 174 pp. Col. «Value Inquiry Book Series», $n^{2} 32$.
}

We must begin by considering what moral dilemmas are for the author of this very interesting, although not completely successful, work, Daniel Statman. A main problem is his very definition of a moral dilemma, and the initial picture of all his research project, a long and winding road around the project of reaching a strong and more rationalistic theory of morals:

"Moral dilemmas are puzzling situations, where agents seem to be under an obligation both to do, and to refrain from doing, a specific act. The possibility that such situations exist has been a matter of great controversy in the last decade. Some philosophers have argued that dilemmas are possible and, therefore, real. This view is often connected to other prevalent ideas in contemporary ethics, the idea of moral luck, and the «anti-theory» trend. Other philosophers have argued that dilemmas are impossible. In this view, we can never be under two real, «all-things-considered» obligations. This latter view is the one endorsed in the present book. I seek to show that dilemmas do not point to any inconsistency in our ethical reasoning nor do they justify giving up the idea of an ethical theory. This does not imply that dilemmas are not troubling, or that they are not the source of justifiable strong negative feelings. They are, and I try to show why. If the argument of the book is sound, it will 
constitute a modest contribution to a more «rationalistic» view of ethics and to what Robert Louden recently called «the re-affirmation of moral theory» (1992).“ [p. 3]

Beside the general difficulties caused by the problematic character of the very researching point of this work, there are other precise objections to raise, for example, the complete disregard of a major figure in contemporary ethics, Lawrence Kohlberg, who makes a deep development and use of moral dilemmas inside his theory of human moral growth. But this is not the only absence.

In the first chapter, the author approaches what is one of his main objectives: to show that moral dilemmas in reality are not such, that they do not exist properly. One of his key arguments is that the difference between the supposed moral dilemmas and the daily moral conflicts rests in the quantity of the "wrong" that purportedly it is at stake in each situation, but it does not depend on any specific property of the situation.

From this point of view, what in reality seems to occur with the agents in a moral dilemma is that are found in an uncertainty situation insofar as the real nature of the options that have before himself is unknown. It is this lack of definition and not the same nature of the situation what seems to be in the origin of the appearance of a dilemma. Again, Daniel Statman tries a rationalistic solution to the ethical problem constituted by moral dilemmas, forgetting that it can have other approaches. For example, the modern theory of moral education has indicated clearly that an individual can deal with a moral dilemma through no fault of information but due to lack of motivation, to lack of an adequate development of the moral will.

The rationalism of the author of this work adopts its maximum expression in the second chapter, where a notion appears that, though seems to discuss the issue of the moral dilemmas, in reality considers it solved. Thus, the basic thesis of Daniel Statman in this work is that a correct solution exists, and only one, for each situation morally conflicting. This Statman calls "The Right Answer Thesis".

Without looking at the problems of asserting the existence of a principle of this type, Statman says to us that this principle consists of two parts: the first part asserts that moral dilemmas have a right answer, and the second asserts, it is evident, that moral dilemmas are not real but constitute distorted situations, mainly due to lack of information in the agents.

The principal objection against the principle of right response to the moral dilemmas formulated by the author of this work arises from utilitarianism. According to this theory in its contemporary formulations there is no rational solution to a moral dilemma because the values in conflict are incommensurable. The only one solution that the author considers is not to change of strategy in the treatment of the moral dilemmas, resigning to his hard theory of rationality, or at least widening it, but intends to escape to the objection of the incommensurability of moral preferences establishing something obvious, this is, that the incommensurability does not prevent the comparability.

As Statman himself indicates, the objection of the incommensurability in reality is putting in question the same purpose in all his research project: the construction of an ethical theory in strong sense and with a clearly rationalistic character. 
It is interesting to this respect that, though Daniel Statman handles a wide classic and contemporary bibliography, within it he includes for example James Griffin (Whitechapel Professor at Oxford University); however he does not use the argument of this same author in connection with the problems of the so-called strong ethical theories.

Regardless of these problems mentioned, and if we must emphasise some especially meritorious point in this work, indeed this would be its idea according to which "the ongoing discussion over the so-called reality of moral dilemmas is not a genuine one, or at least, is far less interesting and important than is usually thought." (P. 149) This interesting idea connects with the position, formulated for example by Dale Jamieson, according to which the abusive use of moral dilemmas in the contemporary ethical theory, darkens more than clarifies its work.

Beyond this criticism to the contemporary role of moral dilemmas is the problematic character of the global project that this work defends: the construction of a new ethical rationality in strong sense. This proposal implies to introduce Ethics in a long and winding road, a distant way to complete, and maybe impossible, rationality.

José L. Tasset Professor of Ethics at A Coruña University, Spain 